\title{
Echoviruses are a major cause of aseptic meningitis in infants and young children in Kuwait
}

\author{
Ajmal Dalwai, Suhail Ahmad, Widad Al-Nakib*
}

\begin{abstract}
Background: The etiologic agents of aseptic meningitis (AM) often include human enteroviruses. The role of enteroviruses causing AM in young children was investigated during a 3-year period in Kuwait.

Results: Enteroviral RNA was detected in cerebrospinal fluid (CSF) by reverse transcription-PCR and specific genotypes of enteroviruses were identified by direct DNA sequencing of VP4-VP2 region. Enteroviral RNA was detected in 92 of 387 (24\%) suspected AM cases and the results were confirmed by hybridization of amplicons with an internal, enterovirus-specific probe. The CSF samples from 75 of 281 (27\%) children <2 years old but only from 3 of 38 (8\%) 4-12 year-old children were positive for enteroviral RNA ( $p=0.011)$. Majority of infections in children $<2$ years old (49 of 75,65\%) were due to three echoviruses; echovirus type 9 (E9), E11 and E30. Only three other enteroviruses, namely coxsackievirus type B4, coxsackievirus type B5 and enterovirus 71 were detected among AM cases in Kuwait.

Conclusions: Our data show that three types of echoviruses (E9, E11 and E30) are associated with the majority of AM cases in Kuwait. To the best of our knowledge, this is the first report to characterize different enterovirus genotypes associated with AM in the Arabian Gulf region.
\end{abstract}

\section{Introduction}

Aseptic meningitis (AM) is a severe, potentially fatal infection of the central nervous system (CNS) and is characterized by meningeal inflammation that is not associated with any identifiable bacterial pathogen in the cerebrospinal fluid (CSF) [1]. Most patients with AM present with abrupt onset of fever accompanied by complaints of headache, stiff neck, lethargy, anorexia, and may also experience vomiting, diarrhea, sore throat and rash. The CNS involvement in neonates may not be accompanied by overt signs of meningeal inflammation. The AM is frequently caused by viral agents, particularly the human enteroviruses (EVs) belonging to the family Picornaviridae [1,2]. More than 10,000 cases of AM are reported annually to The Centers for Disease Control and Prevention. Children are more susceptible than adults to infections by these viruses [3]. The CNS disease in newborns caused by EVs may also progress to

\footnotetext{
* Correspondence: widad@hsc.edu.kw

Department of Microbiology, Faculty of Medicine, Kuwait University, Kuwait
}

meningoencephalitis with the appearance of seizures and focal neurological deficits [1,2].

The EVs are small, nonenveloped, single stranded RNA viruses that are transmitted mainly through fecal oral route and can cause sporadic cases, outbreaks and epidemics [4]. The EVs have been classified into 68 distinct serotypes and new enteroviruses are being described based on molecular characterization $[5,6]$. The capsids of EVs are made up of four structural proteins (VP1 to VP4) of which VP1 as well as VP4-VP2 region sequences have been used for typing human EVs $[7,8]$. In the U. S., some serotypes such as coxsackievirus type B5 (CB5), echovirus 6 (E6), E9 and E30 were associated with epidemics and outbreaks in various years during 2003-2005 while others such as coxsackievirus type A9 (CA9), CB3 and CB4 and enterovirus 71 (EV-71) were endemic throughout the period [9]. During 1998 to 2001, EV-71 was associated with several outbreaks in Taiwan with hand, foot and mouth disease and severe encephalitis while more recently several outbreaks of AM due to E30 have been reported [6,9-12]. Most 
studies have shown that predominant strains of enteroviruses change over time at a given location and majority of infections are seen during summer to fall season $[1,2,11,13]$. On the contrary, a persistence of AM cases due to EVs in winter months was preceded by a large outbreak in spring and summer in France in 1999 [14]. Although AM usually has a benign course and treatment options are limited, surveillance of AM due to EVs is crucial for early identification of such cases to avoid further testing, inappropriate use of antimicrobials and to arrest intrafamilial spread of EV infection $[2,15]$. There is no information on the role of EVs causing AM in Kuwait or other adjoining countries in the Arabian Gulf region of the Middle East. This 3-year study was carried out to determine the role and type of EVs causing AM cases in Kuwait, an Arabian Gulf country in the Middle East, and the results obtained are reported here.

\section{Results}

\section{Demographic and clinical data}

During the three-year period of this study, CSF samples from 387 suspected AM patients were collected and investigated for enteroviral RNA. Of these, 281 (73\%), $68(18 \%)$ and $38(10 \%)$ samples were obtained from children $<2$ years of age, 2-4 years old and 4-12 year old, respectively. The number and percentage of patients in different age groups presenting with symptoms suggestive of AM are shown in Table 1. Symptoms of fever, flu-like illness, poor appetite and signs of meningeal inflammation were apparent in vast majority of children (Table 1).

\section{Detection of enteroviral RNA by RT-PCR and probe hybridization}

Overall, enteroviral RNA was detected in 92 of 387 (24\%) patients by single step RT-PCR (Table 2). All RTPCR-positive amplicons also yielded a positive hybridization signal with an internal enterovirus-specific probe, as expected. The positivity for enteroviral RNA in CSF samples varied among children of different age groups and was significantly lower in older children. Thus, 75 of 281 (27\%) CSF samples from children <2 years old were positive for enteroviral RNA while only 3 of 38 (8\%) samples from older (4-12 years) children were positive for enteroviral RNA $(p=0.011)$. The positivity for enteroviral RNA in CSF samples from children 2-4 years old was also higher compared to older children (14 of $68,21 \%$ Vs. 3 of $38,8 \% ; p=0.088$ ) but slightly lower than in children $<2$ years of age (14 of $68,21 \%$ Vs. 75 of $281,27 \%$; $p=0.3$ ), but the differences were not statistically significant (Table 2). Consistent with earlier reports $[1,2]$, two distinct peaks of enteroviral activity were also noted in Kuwait with majority of enteroviral infections occurring during summer (May-June) and fall (Nov.-Dec.) months in each year of the three-year study period (data not shown).

\section{Genotype classification of enteroviruses by DNA sequencing of VP4-VP2 region}

Based on VP4-VP2 region sequencing, only six genotypes were detected and their occurrence was sporadic indicating that no outbreaks of enteroviral AM occurred during the three-year period in Kuwait. The robustness of VP4-VP2-based genotypic classification was checked by virus isolation and antibody neutralization test from sixteen selected enterovirus-positive CSF samples. In each case, the serotype identified by virus neutralization test was identical to the genotypic classification based on VP4-VP2 sequencing (data not shown). The VP4VP2 region sequences of different enteroviruses from Kuwait exhibited $92 \%$ to $97 \%$ identity with the prototype strains of various specific enteroviruses. Majority (60 of 92, 65\%) of enteroviral AM cases in Kuwait were caused by three types of echoviruses, E9, E11 and E30 (Table 3). The E9 and E11 alone accounted for the majority (43 of 75, 57\%) of infections while EV-71 and CB5 were the other two common genotypes causing AM in children $<2$ years of age. Interestingly, $97 \%$ (29 of 30) of E9

Table 1 Clinical data for $<2$ year old $(n=281), 2-4$ year old $(n=68)$ and 4-12 year old $(n=38)$ children who presented with symptoms of aseptic meningitis

\begin{tabular}{cccc}
\hline Disease symptoms & \multicolumn{3}{c}{ No. (\%) of subjects presenting with symptoms in } \\
\cline { 2 - 4 } & <2 year old & $\mathbf{2 - 4}$ year old & 4-12 year old \\
\hline Fever & $281(100)$ & $68(100)$ & $38(100)$ \\
\hline Flu-like symptoms & $257(91)$ & $65(96)$ & $38(100)$ \\
\hline Poor appetite & $275(98)$ & $45(66)$ & $33(87)$ \\
\hline Photophobia & N.D. & $54(79)$ & $27(71)$ \\
\hline Disturbed consciousness & $125(44)$ & $12(18)$ & $0(0)$ \\
\hline Rash & $136(48)$ & $11(16)$ & $2(5)$ \\
\hline Signs of meningeal inflammation & $227(81)$ & $35(51)$ & $32(84)$ \\
\hline
\end{tabular}

N.D., not determined. 
Table 2 Positivity for enteroviral RNA in cerebrospinal fluid (CSF) samples from suspected aseptic meningitis cases among children of various age groups in Kuwait

\begin{tabular}{cccc}
\hline Age of subjects & Total no. of CSF samples analyzed & No. of CSF samples positive for enteroviral RNA & \% Positivity \\
\hline$<2$ years & 281 & $75^{*}$ & 27 \\
\hline $2-4$ years & 68 & 14 & 21 \\
\hline $4-12$ years & 38 & $3^{*}$ & 8 \\
\hline All subjects & 387 & 92 & 24 \\
\hline
\end{tabular}

*Difference statistically significant $(p=0.011)$.

infections and 93\% (14 of 15) of EV-71 infections were seen among children $<2$ yrs old (Table 3$)$. The different genotypes in AM cases in older children were more evenly distributed (Table 3).

\section{Discussion}

This three-year study investigated the role of EVs in suspected AM cases in Kuwait. The enteroviral RNA was detected by a sensitive, one-step RT-PCR assay that could detect as few as 50 copies of enteroviral genome [16] and the reproducibility of the assay was periodically checked by both internal as well as external National External Quality Assurance Testing (UK-NEQAS) with consistent performance. This is important since $\sim 34 \%$ of various in-house RT-PCR assays developed for enterovirus detection have been reported to fail quality testing [17]. The enteroviral meningitis cases by different EVs were scattered throughout the period of the study and no outbreaks were observed. Furthermore, all major enterovirus genotypes were detected every year except E30 that appeared during the third year of the study. The frequency of enteroviral AM in 92 of 387 (24\%) infants and young children in Kuwait is comparable with annual surveillance data from countries such as USA, UK and some other countries [9,14,18,19] but slightly lower than that reported from other countries such as Spain and Canada [20,21]. Data from the Middle East is generally lacking. Few reports based on virus isolation procedures have found a much lower frequency of enterovirus meningitis in Jordan and Tunisia [22,23]. On the contrary, much higher frequency of enterovirus meningitis has been observed in outbreaks caused by different enteroviruses [6,10,12,24].
The majority (75 of $92,82 \%$ ) of the enteroviral meningitis cases were among children $<2$ yrs of age. Furthermore, the frequency of AM cases in children $<2$ yrs of age (75 of $281,27 \%)$ was significantly higher than the frequency ( 3 of $38,8 \%$ ) seen in older (4-12 year) children $(p=0.011)$. The findings are consistent with earlier observations showing that infants and young children, due to their developing immune system, are more susceptible to enteroviral infections $[1,13]$. Enteroviral infections in older children are less common and are often associated with recreational water activities [2].

The VP1 region has been mostly used for genotypic classification of enteroviruses since antibody neutralizing epitopes are generally located on surface exposed loops of this protein, however, other investigators have also successfully used VP4-VP2 region for genotyping of enteroviruses $[8,25]$. We also used sequencing of VP4VP2 region and the genotypic classification based on this approach for a selected panel of enterovirus-positive samples was completely concordant with the serotype obtained by virus neutralization test. A recent study has also shown complete concordance between enterovirus genotypes determined by sequencing of VP1 region with those derived from VP4 and VP2 regions [26]. Only six genotypes of EVs were detected with nucleotide sequence identities ranging from $92 \%$ to $97 \%$ over the entire length of the $\sim 650$-bp amplicons with the prototype strains of different enteroviruses. The data are consistent with reports that only few dominant genotypes are endemic causing sporadic AM cases in a given geographical setting [1,2]. The three echoviruses (E9, E11 and E30) caused majority (60 of $92,65 \%)$ of AM cases in Kuwait with E9 being most common. Echoviruses,

Table 3 Distribution of specific enterovirus genotypes among enterovirus-positive cerebrospinal fluid samples of suspected aseptic meningitis cases from children of various age groups in Kuwait

\begin{tabular}{cccccccc}
\hline Age of subjects & No. of enterovirus positive samples & \multicolumn{5}{c}{ No. (\%) of specific enterovirus genotypes identified } \\
\cline { 2 - 7 } & & CB4* & CB5 & E9 & E11 & E30 & EV-71 \\
\hline$<2$ years & 75 & $1(1)$ & $11(15)$ & $29(39)$ & $14(19)$ & $6(8)$ & $14(19)$ \\
\hline 2-4 years & 14 & $2(14)$ & $2(14)$ & $1(7)$ & $5(36)$ & $3(21)$ & $1(7)$ \\
\hline 4-12 years & 3 & $0(0)$ & $1(33)$ & $0(0)$ & $2(67)$ & $0(0)$ & $0(0)$ \\
\hline All subjects & 92 & $3(3)$ & $14(15)$ & $30(33)$ & $21(23)$ & $9(10)$ & $15(16)$ \\
\hline
\end{tabular}

*CB4: coxsackievirus type B4; CB5: coxsackievirus type B5; E9, echovirus type 9; E11: echovirus type 11; E30, echovirus type 30; EV-71: enterovirus 71. 
particularly E6, E9 and E30 have also been most commonly found in both, sporadic and outbreak AM cases in USA, Canada and several other countries [2,9,11,21]. The E30 which has recently been associated with outbreaks in several countries was less common while E6 was not even detected in Kuwait. The lower frequency of E30 and absence of E6 infections could be related to the absence of any outbreaks of AM in Kuwait during the study period. The detection of E11 as the second most common etiologic agent of enteroviral meningitis was rather surprising and may be related to its higher occurrence in the Middle-Eastern region. The detection of EV-71, mostly found in Southeast and East Asian countries, in younger children is most likely due to the presence of a large number of expatriate population originating from this region that works as domestic helpers in Kuwait $[27,28]$.

A limitation of the present study is the large number (76\%) of AM cases that did not have an enteroviral etiology. It is probable that some of the enterovirus-negative samples were due to lack of extraction of viral RNA or presence of PCR inhibitors in nucleic acid recovered from these clinical samples since no internal control was used with each sample. Other possible explanations for the lower positivity may include delay in reporting to the hospital after the onset of AM as the initial symptoms of fever and vomiting commonly seen in younger children are often regarded as routine. Furthermore, these cases are usually referred to the hospital by peripheral polyclinics where the patients first report. Studies have shown that the higher positivity of RT-PCR is obtained if CSF samples are collected at an early stage after the onsent of $\mathrm{AM}$, typically within two days, due to declining viral load [29]. It has also been shown that many of the RT-PCR positive specimens remain virus culture negative due to lower viral load. A recent study from Japan showed that virus culture-positive CSF samples contained significantly higher echovirus genome copy numbers than did virus culture-negative CSF samples and E9 was the predominant echovirus identified [30]. Since E9 has also been found to attain higher viral load in CSF specimens in Kuwait [16], it is probable that its increased detection in AM cases is related to the higher load of this virus in CSF samples than other EVs. It is also probable that at least some of the cases were classified as AM due to prior treatment with antibiotics, non-infectious etiologies as a result of certain drug ingestions (such as amoxicillin- or ibuprofen- or trimethoprim-sulfamethoxazole-induced AM) or due to other viral agents that were not explored in this study [1,2]. To the best of our knowledge, this is the first report providing data on the prevalence and association of specific enterovirus genotypes with AM in the Arabian Gulf region.

\section{Materials and methods Patient's data}

This study prospectively identified 387 children $<12$ years of age who were admitted from September 2003 to August 2006 to the paediatric units of two major (Mubarak Al-Kabir and Adan) hospitals in Kuwait with the clinical diagnosis of AM. All children underwent lumbar puncture for collection of cerebrospinal fluid (CSF) which was routinely cultured for common bacterial pathogens in the hospital microbiology laboratory and a portion of CSF sample was transported to the Reference Virology Laboratory, Faculty of Medicine, Kuwait University where RT-PCR tests and virus culture for enteroviruses were performed. The study was approved by the Ethics Committee of the Faculty of Medicine, Kuwait University. Demographic, laboratory and clinical data were collected. Laboratory findings included CSF pleocytosis and absence of bacterial growth. A case was defined as $\mathrm{AM}$ based on the following criteria: fever $\left(>38^{\circ} \mathrm{C}\right)$, symptoms and signs of meningeal inflammation, CSF white blood cell count $>5 \times 10^{6}$ cells/l and negative CSF bacterial culture.

\section{Viral RNA isolation}

The viral RNA was isolated from the CSF samples, typically within one working day, using the viral RNA isolation kit (Qiagen) according to manufacturer's instructions and as described previously [16]. For the detection of enteroviral RNA by reverse transcription-PCR (RT-PCR), $1 \mu \mathrm{l}$ of extracted RNA was used.

\section{Detection of enteroviral RNA}

Enteroviral RNA was detected in RNA samples by using the RT-PCR kit (Qiagen) and a sensitive, one-step RTPCR protocol described previously [16]. The samples were analyzed by agarose gel electrophoresis, as described previously [31]. The reproducibility of the assay was periodically checked by both internal as well as external National External Quality Assurance Testing (UK-NEQAS) with consistent performance.

\section{Southern blotting and hybridization}

The enterovirus-specific identity of amplicons was confirmed by Southern hybridization using an enterovirus-specific biotin-labeled probe, EVKP (5'-biotinATTGTCACCATAAGCAGCCA-3' corresponding to nucleotide positions 601 to 582 of prototype E9 strain DM, GenBank accession number AF524867). The amplicons, after agarose gel electrophoresis, were transferred onto positively charged nylon membranes and the hybrids were detected by using anti-biotin antibodies as described previously $[16,31]$. 


\section{Viral isolation in cell culture}

The virus was isolated from some selected samples by using African green monkey kidney (Vero) and HeLa cells cultured in a monolayer on 24-well microplates. The cells were cultured for at least two weeks at $37^{\circ} \mathrm{C}$ and were periodically checked for characteristic cytopathogenic effect. If a cytopathogenic effect was observed, the sample was considered as virus-culture positive. The isolated virus was subsequently identified by virus neutralization test using neutralization antiserum specific to each enterovirus.

\section{Genotyping of enteroviruses by DNA sequencing}

A DNA fragment ( $\sim 650 \mathrm{bp})$ covering the hypervariable VP4-VP2 region [8] of enteroviral genome was amplified from each enterovirus-positive CSF sample by using the one-step RT-PCR protocol described above except that primers EVK1 (5'-GACTACTTTGGGTGTCCGTGT-3' corresponding to nucleotide positions 543 to 563 of prototype E9 strain DM, GenBank accession number AF524867) and EVK2 (5'-GGTAAYTTCCACCACCANCC-3' corresponding to nucleotide positions 1197 to 1178 of prototype E9 strain DM, GenBank accession number AF524867) were used. A portion $(5 \mu \mathrm{l})$ of the RT-PCR product was run on agarose gel to confirm the amplification of a DNA fragment of expected size and the remaining sample was purified by using QIAquick PCR purification columns (Qiagen) as described previously $[32,33]$. Both strands of purified amplicons were sequenced by using cycle DNA sequencing kit (DTCS CEQ8000, Beckman Coulter) as described in detail previously [32,33] except that primer EVK1 or EVK2 were used as sequencing primers. Reverse complements were generated and aligned with forward sequences using ClustalW http://www.ebi.ac.uk/Tools/clustalw/index. html. GenBank identity search using Basic Local Alignment Search Tool (BLAST) http://www.ncbi.nlm.nih. gov/BLAST/Blast.cgi? was performed for genotype identification. A minimum identity of $92 \%$ over the entire length of the amplicons with prototype strains of different enteroviruses was used for genotype assignment [8]. The DNA sequencing data reported in this study have been submitted to EMBL under accession numbers FR687401 to FR687410 and FR690863 to FR690867.

\section{Statistical analyses}

Differences in proportions were compared by using $\chi^{2}$ test. A $P$ value of $<0.05$ was considered as statistically significant. All statistical analyses were performed using WinPepi software ver. 3.8 (PEPI-for Windows).

\section{List of Abbreviations}

AM: aseptic meningitis; CNS: central nervous system; EV: enteroviruses; E9: echovirus 9; E11: echovirus 11;
E30: echovirus 30; CB4: coxsackievirus B4; CB5: coxsackievirus B5; EV-71: enterovirus 71; VP; viral capsid protein.

\section{Author Details}

Virology Unit, Department of Microbiology, Faculty of Medicine, Kuwait University P.O. Box 24923, Safat 13110, Kuwait.

\section{Acknowledgements}

We thank Jassem Abdul-Raheem and Faisal Sulaiman for providing clinical samples. This study was supported by Research Administration grant YM03/ 02 and the College of Graduate Studies, Kuwait University.

\section{Authors' contributions}

SA and WAN designed the study. AD performed the experiments and analyzed the data. All authors contributed in writing and approved the final manuscript.

\section{Competing interests}

The authors declare that they have no competing interests.

Received: 29 June 2010 Accepted: 16 September 2010

Published: 16 September 2010

\section{References}

1. Irani DN: Aseptic meningitis and viral myelitis. Neurol Clin 2008, 26:635-655.

2. Lee BE, Dele Davies H: Aseptic meningitis. Curr Opin Infect Dis 2007, 20:272-277.

3. Rotbart HA: Viral meningitis. Semin Neurol 2000, 20:277-292.

4. Antona D, Leveque N, Chomel JJ, Dubrou S, Levy-Bruhl D, Lina B: Surveillance of enteroviruses in France 2000-2004. Eur J Clin Microbiol Infect Dis 2007, 26:403-412.

5. Mirand A, Henquell C, Archimbaud C, Peigue-Lafeuille $H$, Bailly JL: Emergence of recent echovirus 30 lineages is marked by serial genetic recombination events. J Gen Virol 2007, 88:166-176.

6. Brunel D, Leveque N, Jacques J, Renois F, Motte J, Andreoletti L: Clinical and virological features of an aseptic meningitis outbreak in NorthFrance, 2005. J Clin Virol 2008, 42:225-228.

7. Oberste MS, Maher K, Kilpatrick DR, Flemister MR, Brown BA, Pallansch MA: Typing of human enteroviruses by partial sequencing of VP1. J Clin Microbiol 1999, 37:1288-1293.

8. Ishiko H, Shimada Y, Yonaha M, Hashimoto O, Hayashi A, Sakae K, Takeda N: Molecular diagnosis of Human enteroviruses by phylogeny-based classification by use of the VP4 sequence. J Infect Dis 2002, 185:744-754.

9. Khetsuriani N, Lamonte-Fowlkes A, Oberst S, Pallansch MA: Enterovirus surveillance: United States, 1970-2005. MMWR Surveill Summ 2006, 55:1-20.

10. Lin TY, Twu SJ, Ho MS, Chang LY, Lee CY: Enterovirus 71 outbreaks, Taiwan: occurrence and recognition. Emerg Infect Dis 2003, 9:291-293.

11. Dos Santos GP, Skraba I, Oliviera D, Lima AA, de Melo MM, Kmetzsch Cl, da Costa EV, da Silva EE: Enterovirus meningitis in Brazil, 1998-2003. J Med Virol 2006, 78:98-104.

12. Choi YJ, Park KS, Ah Baek H, Jung EH, Nam HS, Kim YB, Park JS: Molecular characterization of echovirus 30-associated outbreak of aseptic meningitis in Korea in 2008. J Microbiol Biotechnol 2010, 20:643-649.

13. Lee KY, Burgner D, Lee HS, Hong JH, Lee MH, Kang JH, Lee BC: The changing epidemiology of pediatric aseptic meningitis in Daejeon, Korea from 1987 to 2003. BMC Infect Dis 2005, 5:97.

14. Chambon M, Archimbaud C, Bailly JL, Henquell C, Regagnon C, Charbonné $F$, Peigue-Lafeuille $\mathrm{H}$ : Circulation of enteroviruses and persistence of meningitis cases in the winter of 1999-2000. J Med Virol 2001, 65:340-347.

15. Kuramitsu M, Kuroiwa C, Yoshida H, Miyoshi M, Okumura J, Shimizu H, Narantuya L, Bat-Ochir D: Nonpolio enterovirus isolation among families 
in Ulaanbaatar and Tov province, Mongolia, intrafamilial spread, and risk factors for infection. Epidemiol Infect 2005, 133:1131-1142.

16. Dalwai A, Ahmad S, Pacsa A, Al-Nakib W: Echovirus 9 is an important cause of encephalitis in infants and young children in Kuwait. J Clin Virol 2009, 44:48-51.

17. van Vliet KE, Muir $P$, Echevarria JM, Klapper $P E$, Cleator GM, van Loon AM: Multicenter proficiency testing of nucleic acid amplification methods for the detection of enteroviruses. J Clin Microbiol 2001, 39:3390-3392.

18. Maguire $\mathrm{HC}$, Atkinson P, Sharland M, Bendig J: Enterovirus infections in England and Wales: laboratory surveillance data: 1975 to 1994 . Commun Dis Pub Health 1999, 2:122-125.

19. Druyts-Voets E: Epidemiological features of entero non-poliovirus isolations in Belgium 1980-94. Epidemiol Infect 1997, 119:71-77.

20. Trallero G, Casas I, Tenorio A, Echevarria JE, Castellanos A, Lozano A, Brena PP: Enteroviruses in Spain: virological and epidemiological studies over 10 years (1988-97). Epidemiol Infect 2000, 124:497-506.

21. Lee BE, Chawla R, Langley JM, Forgie SE, Al-Hosni M, Baerg K, Husain E, Strong J, Robinson JL, Allen U, Law BJ, Dobson S, Davies HD: Paediatric investigators collaborative network on infections in Canada (PICNIC) study of aseptic meningitis. BMC Infect Dis 2006, 6:68.

22. Meqdam MM, Khalousi MM, Al-Shurman A: Enteroviral meningitis in northern Jordan: prevalence and association with clinical findings. $J$ Med Virol 2002, 66:224-228.

23. Bahri O, Rezig D, Nejma-Oueslati BB, Yahia AB, Sassi JB, Hogga N, Sadraoui A, Triki H: Enteroviruses in Tunisia: virological surveillance over 12 years (1992-2003). J Med Microbiol 2005, 54:63-69.

24. Khalfan S, Aymard M, Lina B, Thouvenot D, Schuffenecker I, Foray S, Fernandes E, Baig B: Epidemics of aseptic meningitis due to enteroviruses following national immunization days in Bahrain. Ann Trop Paediatr 1998, 18:101-109.

25. Nasri D, Bousalama L, Omar S, Saoudin H, Bourlet T, Aouni M, Pozzetto B, Pillet S: Typing of human enteroviruses by partial sequencing of VP2. J Clin Microbiol 2007, 45:2370-2379.

26. Perera D, Shimizu H, Yoshida H, Tu PV, Ishiko H, McMinn PC, Cardosa MJ: A comparison of the VP1, VP2 and VP4 regions for molecular typing of human enteroviruses. J Med Virol 2010, 82:649-657.

27. Ahmad S, Mokaddas E: Contribution of AGC to ACC and other mutations at codon 315 of the katG gene in isoniazid-resistant Mycobacterium tuberculosis isolates from the Middle East. Int J Antimicrob Agents 2004 23:473-479.

28. Mokaddas E, Ahmad S, Samir I: Secular trends in susceptibility patterns of Mycobacterium tuberculosis isolates in Kuwait, 1996-2005. Int J Tuberc Lung Dis 2008, 12:319-325.

29. Kupila L, Vuorinen T, Vainionpäā R, Marttila RJ, Kotilainen P: Diagnosis of enteroviral meningitis by use of polymerase chain reaction of cerebrospinal fluid, stool, and serum specimens. Clin Infect Dis 2005, 40:982-987.

30. Fujimoto T, Izumi H, Okabe N, Fujimoto T, Izumi H, Okabe N: Usefulness of real-time reverse transcription-polymerase chain reaction for the diagnosis of echovirus aseptic meningitis using cerebrospinal fluid. Jap J Infect Dis 2009, 62:455-457.

31. Ahmad S, Mustafa AS, Khan Z, Al-Rifaiy Al, Khan ZU: PCR-enzyme immunoassay of rDNA in the diagnosis of candidemia and comparison with amplicon detection by agarose gel electrophoresis. Int J Med Microbiol 2004, 294:45-51.

32. Ahmad S, Mokaddas E, Jaber A-A: Rapid detection of ethambutol-resistant Mycobacterium tuberculosis strains by PCR-RFLP targeting embB codons 306 and 497 and iniA codon 501 mutations. Mol Cell Probes 2004, 18:299-306.

33. Ahmad S, Mokaddas E: The occurrence of rare rpoB mutations in rifampicin-resistant Mycobacterium tuberculosis isolates from Kuwait. Int $J$ Antimicrob Agents 2005, 26:205-212.

doi:10.1186/1743-422X-7-236

Cite this article as: Dalwai et al:: Echoviruses are a major cause of aseptic meningitis in infants and young children in Kuwait. Virology Journal 2010 7:236.

\section{Submit your next manuscript to BioMed Central and take full advantage of:}

- Convenient online submission

- Thorough peer review

- No space constraints or color figure charges

- Immediate publication on acceptance

- Inclusion in PubMed, CAS, Scopus and Google Scholar

- Research which is freely available for redistribution

Submit your manuscript at www.biomedcentral.com/submit
CioMed Central 